\title{
LIBERALISMO IGUALITÁRIO, DIREITO PRIVADO E VALORES BILATERAIS
}

\section{LIBERAL EGALITARIANISM, PRIVATE LAW AND BILATERAL VALUES}

LEANDRO MARTINS ZANITELLI ${ }^{1}$

RESUMO: O artigo trata da relação entre justiça distributiva e o que Samuel Scheffler (2015) designa como "valores bilaterais" do direito privado. Em primeiro lugar, reconstrói-se o argumento de Scheffler sobre o liberalismo igualitário submeter o direito privado a um distributivismo forte - isto é, requer que o direito privado se conforme a princípios de justiça distributiva como o princípio da diferença. Em segundo lugar, o conceito de valor bilateral (como valor potencialmente conflitante com a justiça distributiva) é esmiuçado. Por último, o artigo parte de uma lista provisória de valores bilaterais do direito privado para avaliar a afirmação de que o distributivismo forte constitui uma ameaça a esses valores. Conclui-se que, ao menos em alguns casos, o conflito entre justiça distributiva e valores bilaterais é restrito a condições não ideais (isto é, condições de não conformidade à justiça).

Palavras-Chave: Direito Privado; Liberalismo Igualitário; Justiça Distributiva; Valores Bilaterais.

ABSTRACT: The paper addresses the relation between distributive justice and what Scheffler (2015) refers to as private law's 'bilateral values'. The first section reconstructs Scheffler's argument about liberal egalitarianism's strong distributive implications for private law. In the second section, the concept of bilateral value (as a potentially conflicting value with distributive justice) is rendered more precise. In the third and last section, the articles draws on a provisory list of private law's bilateral values in order to assess the claim according to which liberal egalitarianism's strong distributivism represents a threat to those values. It is asserted that, at least in some

${ }^{1}$ Doutor em Direito pela UFRGS; Professor Adjunto na Faculdade de Direito da UFMG O autor agradece à FAPEMIG pelo financiamento do projeto de pesquisa do qual este artigo é resultado. Meus sinceros agradecimentos vão também para os editores da Revista Estudos Institucionais e a dois pareceristas anônimos pelos comentários e sugestões feitos à versão anterior do trabalho. E-mail: leandrozanitelli@gmail.com. 
instances, the conflict between distributive justice and bilateral values is restricted to non-ideal conditions.

KEYWORDS: Private Law; Liberal Egalitarianism; Distributive Justice; Bilateral Values.

\section{INTRODUÇÃo}

Este artigo trata do problema do distributivismo no direito privado. Em um trabalho recente sobre as implicações do liberalismo igualitário para o direito privado, Samuel Scheffler (2015) diferencia dois pontos-de-vista sobre a aplicação ao direito privado de princípios de justiça distributiva (como o princípio da diferença de Rawls). Um desses pontos-de-vista, mais moderado (distributivismo fraco), é elogiado por Scheffler por não fazer demandas incompatíveis com certos valores próprios do direito privado (que Scheffler designa como "valores bilaterais"). Ele admite, porém, que o distributivismo fraco pode não ser defensável nem se diferenciar tanto, por suas implicações, de uma versão mais ambiciosa de distributivismo (distributivismo forte).

O texto a seguir se propõe a fazer as seguintes contribuições. A primeira seção reconstrói o argumento de Scheffler acerca das implicações distributivas do liberalismo igualitário para o direito privado. Além de reproduzir as razões pelas quais o distributivismo fraco deve, de fato, ser posto de lado, a seção procura apresentar de maneira mais precisa as consequências do distributivismo forte. A segunda seção se volta ao conceito de valores bilaterais e encerra com uma lista provisória desses valores. A terceira seção, a mais importante, parte da lista de valores bilaterais introduzida na seção anterior para testar a afirmação de que a justiça distributiva (em particular, o distributivismo forte) é uma ameaça a esses valores. A conclusão é que, ao menos para alguns valores bilaterais, a relação com a justiça distributiva é mais uma relação de dependência do que de oposição. Valores bilaterais são dependentes da justiça distributiva no sentido de que a sua realização institucional em condições ideais só é defensável nos termos de instituições que se conformam elas mesmas à demanda distributiva característica do liberalismo igualitário.

\section{LIBERALISMO IGUALITÁRIO, DISTRIBUTIVISMO E DIREITO PRIVADO}

Em um artigo sobre a situação do direito privado em concepções liberais igualitárias de justiça, Scheffler (2015) alerta para a incompatibilidade entre as implicações distributivas dessas concepções e os valores bilaterais do direito privado. Nesta primeira seção, o objetivo é reproduzir e detalhar o argumento de Scheffler sobre a tensão entre o distributivismo liberal igualitário e o direito privado. ${ }^{2}$

2 Apesar de conter a expressão private law em seu título, o artigo de Scheffler frequentemente se refere ao direito contratual. Presume-se acima que as afirmações de Scheffler sobre o direito contratual no

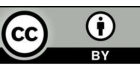


Referindo-se, em particular, à concepção de justiça de John Rawls, Scheffler afirma que dela se podem retirar diferentes injunções distributivas para o direito privado. ${ }^{3}$ Scheffler diferencia, a esse respeito, de acordo com a força dessas injunções, um distributivismo fraco e um forte (veremos logo a seguir, no entanto, que, com base nas considerações de Scheffler, é possível distinguir quatro, e não apenas duas, espécies de distributivismo).

Em primeiro lugar, o distributivismo fraco leva em consideração o princípio da diferença ${ }^{4}$ em combinação com outros dois princípios da concepção rawlsiana de justiça, os princípios das liberdades básicas e da equitativa igualdade de oportunidades. ${ }^{5}$ Como, ademais, esses princípios gozam de prioridade léxica sobre o princípio da diferença, uma implicação do distributivismo fraco é que o direito privado só deve atender ao princípio da diferença caso, ao fazê-lo, não atente contra algum dos outros dois princípios. Em segundo lugar, o distributivismo fraco também modera a demanda distributiva do liberalismo igualitário ao requerer que o direito privado seja desenhado tão-somente de maneira não piore a situação dos cidadãos menos favorecidos (ao invés de requerer que a situação desses cidadãos seja maximizada) (Scheffler 2015, p. 222). Em contrapartida, o distributivismo forte se caracteriza por desconsiderar os limites à aplicação do princípio da diferença decorrentes dos outros dois princípios, bem como por demandar que o direito privado seja conformado de molde a beneficiar na maior medida possível (ao invés de apenas não piorar) a situação dos cidadãos em desvantagem. ${ }^{6}$

geral se apliquem às demais partes do direito privado, em particular os direitos da propriedade, empresa e responsabilidade civil.

${ }^{3}$ Ao fazê-lo, Scheffler (2015, p.217-222) rejeita a tese de que o direito privado não pertença à estrutura básica da sociedade - o conjunto de instituições às quais se aplicam os princípios da justiça rawlsiana.

${ }^{4} \mathrm{O}$ princípio da diferença requer que desigualdades na distribuição do que Rawls (2001, p. 42-43) designa como "bens primários" beneficiem na maior medida possível os cidadãos em desvantagem.

${ }^{5}$ Sobre o princípio das liberdades básicas, ver Rawls (2001, p. 42): "[e]ach person has the same indefeasible claim to a fully adequate scheme of equal basic liberties, which scheme is compatible with the same scheme of liberties for all". O princípio da equitativa igualdade de oportunidades requer iguais oportunidades para ocupar cargos e posições em um sentido mais do que meramente formal: "those who have the same level of talent and ability and the same willingness to use these gifts should have the same prospects of success regardless of their social class of origin" (RAWLS, 2001, p. 44). Na nomenclatura rawlsiana, o princípio das liberdades básicas é o primeiro princípio da justiça, enquanto os princípios da equitativa igualdade de oportunidades e da diferença constituem as duas partes do segundo princípio.

${ }^{6}$ Se considerarmos que o princípio da diferença se aplica a um conjunto de instituições que inclui o direito privado, mas não se limita a ele, é forçoso concluir que, mesmo na versão forte de distributivismo, o princípio da diferença pode ser compatível com um direito privado menos vantajoso para os cidadãos em pior situação do que outro possível. Esse direito privado subótimo (no que concerne à situação dos cidadãos menos favorecidos) se conformaria ao princípio da diferença por fazer parte do arranjo institucional geral mais benéfico aos cidadãos em pior situação. A intuição aqui é que as instituições não exercem seus efeitos independentemente umas das outras, de modo que um direito privado que seja em si mesmo otimamente benéfico para os cidadãos em desvantagem pode interferir negativamente no impacto de outras instituições sobre esses mesmos cidadãos, dando lugar a um arranjo institucional (no seu todo e no que se refere aos cidadãos em pior situação) subótimo. Ao tratar do distributivismo forte, Scheffler não comete o erro de aplicar o princípio da diferença ao direito privado isoladamente, de modo que as considerações acima sobre esse distributivismo devem ser lidas à luz da ressalva feita aqui. 
As duas diferenças entre os distributivismos forte e fraco são completamente independentes uma da outra, o que permitiria distinguir quatro ao invés de apenas duas espécies de distributivismo: um distributivismo forte/forte, ${ }^{7}$ com as duas características acima mencionadas (insubordinação aos demais princípios mais maximização da vantagem dos cidadãos em pior situação; um distributivismo fraco/fraco (subordinação aos demais princípios mais um princípio de não piora ao invés de um princípio de maximização); e dois distributivismos intermediários com uma, mas não outra, dessas características.

Entre parênteses, porém, note-se que é duvidoso que o distributivismo seja de alguma maneira atenuado pela falta da primeira característica. Afinal, os princípios das liberdades básicas e da equitativa igualdade de oportunidades também são, a exemplo do princípio da diferença, princípios de justiça distributiva, distinguindo-se desse último apenas pelos bens de cuja distribuição tratam e por requererem, em geral (e, mais notadamente, o princípio das liberdades básicas), uma igual distribuição (ao invés de uma que maximize a vantagem dos cidadãos menos afortunados). De qualquer maneira, Scheffler (2015, p. 224-225) reconhece que a diferença entre distributivismo forte e fraco é, no tocante à aplicação dos princípios das liberdades básicas e da equitativa igualdade de oportunidades, negligenciável, já que as implicações desses princípios para o direito privado seriam, ao seu ver, modestas.

O segundo critério de distinção, em contraste, é prenhe de consequências. Se o que o princípio da diferença impõe é tão-somente que não haja piora na situação dos cidadãos em desvantagem, então boa parte do conteúdo do direito privado fica por ser determinada com base em outras considerações. A versão forte de distributivismo, em contrapartida, só impediria que o direito privado fosse inteiramente governado pelo princípio da diferença caso diferentes conformações desse direito se mostrassem comparáveis no que toca a promover os interesses dos cidadãos em pior situação.

Depois de menosprezar a importância da primeira diferença entre os distributivismos fraco e forte, Scheffler afirma que, no que respeita à segunda diferença, o distributivismo forte é superior ao fraco. $O$ problema com $o$ distributivismo fraco nesse quesito, diz ele, é definir a situação de referência a partir da qual teríamos de verificar se um certo desenho do direito privado piora a situação dos cidadãos em desvantagem. Se essa situação de referência for aquela na qual o lote de bens primários desses cidadãos é maximizado, as demandas dos distributivismos fraco e forte coincidirão. Poderíamos evitar esse resultado usando uma base de avaliação distinta, mas é duvidoso que o uso de uma certa situação de referência ao invés de outra possa ser justificado (SCHEFFLER, 2015, p. 225).

A conclusão de Scheffler é que liberais igualitários como Rawls parecem fadados a endossar o distributivismo forte ou algo muito parecido com ele. Isso, porém, é um problema, pelas razões que Scheffler expõe na passagem a seguir:

\footnotetext{
$7 \mathrm{Ou}$ até mais - em um total de nove - se quisermos tratar independentemente as questões da subordinação ao princípio das liberdades básicas e ao princípio da equitativa igualdade de oportunidades.
} 
Primeiro, quando as pessoas entram em arranjos contratuais, elas se envolvem em uma atividade que se sobrepõe e se mantém em uma relação complexa (e contestada) com outras formas de compromisso e acordo, como promessas, que implicam valores e normas importantes. Insistir, em um forte espírito distributivista, de que o conteúdo do direito contratual fosse totalmente determinado pelo princípio da diferença, ou por qualquer princípio similar, poderia colocar em risco esses valores e normas. Pode arriscar deslocá-los em favor do requisito abrangente de que os acordos contratuais devem servir aos fins distributivos. Em segundo lugar, muitos dos valores que se aplicam a interações específicas entre indivíduos têm um caráter distintamente relacional. Eles se concentram no nexo que liga os indivíduos em questão. Tais valores são verificáveis quando, por exemplo, falamos do que uma pessoa deve a outra, ou de como uma pessoa pode ter prejudicado outra, ou de como esse prejudicado pode ter uma queixa contra a primeira. Grande parte do direito privado como tradicionalmente concebido tem um caráter similarmente relacional ou "bipolar" [nota de rodapé omitida]. Mas o princípio da diferença não. Preocupa-se com a distribuição geral de bens primários, e não com as relações bilaterais entre particulares. Assim, qualquer exigência distributivista forte de que o conteúdo do direito contratual deva ser inteiramente determinado pelo princípio da diferença poderia ameaçar esses valores bilaterais, da mesma maneira que a abordagem amplamente utilitária associada ao direito e à economia tem sido, às vezes, acusada de fazer (SCHEFFLER, 2015, p223-224, tradução livre). ${ }^{8}$

\section{O argumento de Scheffler parece ter, pois, a seguinte estrutura:}

\footnotetext{
${ }^{8}$ First, when people enter into contractual arrangements, they engage in an activity that overlaps with and stands in a complex (and contested) relation to other forms of commitment and agreementmaking, such as promising, which themselves implicate important values and norms. To insist, in a strong distributivist spirit, that the content of contract law was fully determined by the difference principle, or by any similar principle, might place these values and norms in jeopardy. It might risk displacing them in favour of the one overarching requirement that contractual agreements must serve distributive ends. Second, many of the values that apply to specific interactions between individuals have a distinctively relational character. They focus on the nexus linking the individuals in question. Such values are implicated when, for example, we speak of what one person owes to another, or of the first person as having wronged the second, or of the second as having a complaint against the first. Much of the private law as traditionally conceived has a similarly relational or 'bipolar' character [nota de rodapé omitida]. But the difference principle does not. It is concerned with the overall distribution of primary goods, rather than with bilateral relations between particular individuals. So any strong distributivist requirement that the content of contract law should be entirely determined by the difference principle might threaten these bilateral values, in much the same way that the broadly utilitarian approach associated with law and economics has sometimes been accused of doing
} 
1. Uma vez aplicado ao direito privado sem as restrições do distributivismo fraco, o princípio da diferença (ou qualquer outro princípio similar) determina completamente o conteúdo desse direito.

2. O direito privado é, porém, um direito de estrutura bilateral (ou bipolar), cujos valores são, também, bilaterais.

3. O princípio da diferença (ou qualquer outro princípio similar) versa sobre a distribuição geral de bens primários.

4. Princípios que versam sobre a distribuição geral de bens primários não são princípios (ou valores) bilaterais.

5. A aplicação irrestrita (conforme ao distributivismo forte) do princípio da diferença faz com que o conteúdo do direito privado seja completamente determinado por um princípio diferente dos princípios (ou valores) bilaterais que são próprios a esse direito.

A premissa crucial para este artigo é 2, mas é importante, antes de prosseguir, tratar um pouco mais detidamente da premissa 1 . Afinal, o que se quer dizer com a afirmação de que um princípio determina completamente o conteúdo de uma área do direito? Duas interpretações podem ser aventadas. De acordo com a primeira, um princípio determina completamente o conteúdo de uma área do direito se, em todos os seus pormenores, esse conteúdo é determinado pelo princípio em questão. Afirmar que o direito privado é completamente determinado pelo princípio da diferença, por exemplo, seria, portanto, o mesmo que afirmar que toda dúvida atinente ao conteúdo do direito privado é resolvida com base no princípio da diferença. Uma segunda interpretação, em contrapartida, não requer que toda questão de conteúdo seja respondida em conformidade com um certo princípio. Para essa interpretação, um princípio determina completamente o conteúdo de uma área do direito caso essa área esteja, em sua totalidade, sujeita aos limites do princípio em questão. Isso não quer dizer que, entre os conteúdos $x$ e $-x$, o mesmo princípio tenha algo a dizer. Se ambos os conteúdos forem compatíveis com os limites que impõe, então a dúvida sobre o conteúdo - se $x$ ou $-x$ - não será resolvida por esse princípio.

A primeira interpretação, claro, é absurda. Nenhum princípio - ou nenhum princípio, ao menos, dentre os que costumam povoar tratados sobre justiça - é determinado o suficiente para que consigamos responder com ele a todas as questões de desenho institucional - mesmo que limitadas às instituições de uma certa área do direito. O princípio da diferença, para ficar com o exemplo que Scheffler tem em vista, é indeterminado sobre quem devam ser considerados como cidadãos em pior situação e sobre trade-offs entre os diferentes bens primários de cuja distribuição esse princípio trata e cujo lote - para os cidadãos em pior situação - deve ser maximizado. Mesmo, portanto, que dispuséssemos de informação ilimitada, é provável que o princípio da diferença não nos desse resposta sobre questões de detalhe do direito contratual - por 
exemplo, sobre a regra (da expedição ou recepção) a aplicar quanto à formação dos contratos.

A segunda interpretação não sofre do mal da primeira, mas pode diminuir consideravelmente a gravidade do problema constatado por Scheffler. Se princípios de justiça distributiva como o princípio da diferença apenas impõem limites ao conteúdo do direito privado, sem, contudo, responder a toda e qualquer dúvida atinente a esse conteúdo, ${ }^{9}$ então haverá partes do direito privado cujo fundamento não será distributivo e poderá, portanto, fazer jus aos valores bilaterais a que Scheffler se refere. O espaço concedido a esses valores pelo distributivismo forte dependerá, é claro, do quão determinado o princípio de justiça distributiva se mostrar. ${ }^{10}$

Por certo que, nesse último caso, o distributivismo forte não deixa de ser uma ameaça aos valores bilaterais do direito privado, porque a aplicação desses valores fica, de qualquer maneira, condicionada à observância dos limites definidos pela justiça distributiva. Mas isso é menos do que afirmar a total irrelevância desses valores ou que eles não sejam, em relação a certas questões, a última ratio.

\section{VALORES BILATERAIS: UMA INTRODUÇÃO}

Esta seção se propõe a esmiuçar o conceito de valores bilaterais, bem como a apresentar uma lista provisória desses valores. Scheffler se refere aos valores bilaterais como valores próprios à estrutura, bilateral (ou bipolar), do direito privado. Mas o que isso quer dizer?

A ideia de que o direito privado possua uma estrutura bilateral que o diferencia do direito público pode soar estranha a tradições jurídicas, como a brasileira, às quais é familiar o conceito de relação jurídica. Para quem esteja acostumado a pensar em direitos como parte de uma relação jurídica - mesmo quando se trata de direitos erga omnes - é difícil perceber como a bilateralidade, ou relacionalidade, pode ser peculiar ao direito privado. Afinal, se o contrato faz surgir uma relação jurídica entre os contratantes, o mesmo se diz sobre o fato gerador em relação ao fisco e ao contribuinte.

A diferença entre a relação contratual e a relação fiscal se manifesta no seguinte. Enquanto se pode dizer que o fato gerador constitui uma relação entre o estado e um determinado contribuinte, os valores ou princípios que regulam essa relação não se limitam, em geral, a ela, no sentido de que são valores ou princípios sensíveis à situação ou à atividade de terceiros. Se Maria aufere uma renda $r$ e essa renda é tributada em $40 \%$, isso não é justificado apenas pelo fato de Maria ter auferido $r$. Uma

\footnotetext{
${ }_{9}$ Pode ser estranho dizer que um princípio determina completamente o conteúdo de uma área do direito se há questões sobre esse conteúdo que o princípio em questão é incapaz de responder, mas, tendo em vista o absurdo da primeira interpretação, a segunda interpretação, à falta de uma terceira, parece se impor.

10 Repare que, à luz da segunda interpretação, a diferença entre os distributivismos forte e fraco é meramente de grau. Ao substituir o imperativo de maximização da vantagem dos cidadãos menos favorecidos por um imperativo de não piora, o que o distributivismo fraco faz é afrouxar os limites distributivos a que o direito privado deve se sujeitar.
} 
justificação completa para a tributação da renda de Maria envolve, entre outras coisas, uma comparação entre a renda de Maria e a de outras pessoas.

Em contrapartida, no direito privado - ou, ao menos, em algumas áreas dele, como as dos contratos e da responsabilidade civil - certos valores parecem ser consideravelmente independentes de tudo o que não respeite às partes da relação jurídica - mais precisamente, à sua particular interação. Se A causou dano a B, a relação jurídica entre ambos (A deve indenizar B) pode-se dizer regulada (possivelmente entre outros) pelo valor da responsabilidade, e esse é um valor sensível tão-somente ao que A fez a B. A bilateralidade do direito privado se traduz, pois, nesse e em outros casos, pela incidência de valores atinentes à relação entre as partes e independentes de tudo o que não diga respeito a essa relação.

A diferenciação que se acaba de fazer entre os direitos privado e público não deve ser exagerada. E bem possível que, em certas áreas do que costumamos chamar de direito público, haja relações governadas por valores tão bilaterais ou relacionais como o valor da responsabilidade (a relação de desapropriação pode ser um exemplo). $\mathrm{O}$ importante aqui é menos traçar uma linha divisória clara entre os direitos público e privado e mais esclarecer por que certos valores do direito privado são relacionais em um sentido que, à primeira vista, pode não se dar a perceber, principalmente para os que estão habituados ao conceito de relação jurídica.

Se os valores bilaterais são, portanto, valores próprios à interação das partes e independentes do que não diz respeito a essa interação, quais são esses valores? Segue abaixo uma lista que se deve considerar provisória, porque não há aqui qualquer intenção de justificar esses valores a seguir mencionados. A ideia é termos uma lista de valores bilaterais do direito privado que seja ao menos plausível e que permita voltar, na seção seguinte, ao problema do distributivismo.

Valores bilaterais:

a) propriedade, ou o valor de que um direito de propriedade de B não seja violado por A;

b) promessa, ou o valor de que A cumpra a promessa que fez a B;

c) não coerção, ou o valor de que B não seja coagido por A a fazer $x$;

d) responsabilidade, ou o valor de que A responda pelo dano que, sob certas condições (por exemplo, culposamente), causou a B;

e) cuidado, ou o valor de que A cuide de B sob certas circunstâncias ou tendo em vista a especial relação (por exemplo, familiar) entre A e B.

\section{DIREITO PRIVADO, DISTRIBUTIVISMO E VALORES BILATERAIS}

Conforme vimos na primeira seção, o que Scheffler (2015) chama de distributivismo forte deixaria o liberalismo igualitário em tensão com os valores bilaterais próprios ao direito privado, porque sujeitaria a realização desses valores a certos limites. Uma vez esclarecido em que consistem os valores bilaterais, podemos, a partir da lista provisória apresentada ao final da seção anterior, tratar mais detalhadamente da sua relação com princípios de justiça distributiva. 


\section{1. propriedade}

Um problema aqui é que o liberalismo igualitário se caracteriza - em contraposição ao libertarismo de direita de autores como Nozick (1974) - por negar direitos de propriedade não distributivos (KORDANA; TABACHNICK, 2006). No liberalismo igualitário, direitos de propriedade são (exceção feita ao que pertença ao âmbito das liberdades básicas ${ }^{11}$ ) condicionados a uma "demanda igualitária", isto é, à demanda de que os cidadãos, além de livres, possuam os meios para realizar seus projetos de vida, ${ }^{12}$ o que, no caso da concepção de justiça defendida por Rawls, traduz-se pelas duas partes do segundo princípio de justiça, os princípios da equitativa igualdade de oportunidade e da diferença. Do ponto-de-vista da justiça liberal igualitária, a propriedade só é justificada à medida que se conforme à demanda igualitária.

Pode-se alegar que o fato de a propriedade ser distributivamente condicionada não impede que se trate o valor bilateral da propriedade como um valor independente da justiça distributiva, e por duas razões. Primeiro, e tal como ponderado anteriormente (seção 1), porque não é de esperar que a demanda igualitária conforme completamente a propriedade, no sentido de que não haja direitos contraditórios de propriedade, como os direitos a $x$ e $-x$, que obedeçam, ambos, aos limites dessa demanda, de tal maneira que a escolha entre $x$ e $-x$ tenha de ser feita em termos não distributivos. Segundo, porque, nas circunstâncias não ideais de não observância total aos princípios da justiça liberal igualitária, há direitos jurídicos de propriedade que não atendem à demanda igualitária, mas é plausível que haja um valor no respeito a esses direitos.

Os dois argumentos recém expostos são bem sucedidos em demonstrar que o valor da propriedade deve ser tratado como independente (mesmo por liberais igualitários) da justiça distributiva, mas a vitória é de Pirro, porque, nos dois casos, o valor da propriedade, embora independente da justiça, não é independente do regime jurídico da propriedade. Quando se trata, pois, de reformas desse regime, o valor da propriedade não é contrariado, nem, tampouco, pode se constituir como objeção a propostas de mudança baseadas em considerações de justiça distributiva. ${ }^{13}$

\section{2. promessa}

Ao menos sob certas condições, o valor da promessa também é, a exemplo da propriedade, parasitário da justiça distributiva. A partir do famoso exemplo Wilt

11 As liberdades básicas não costumam incluir, no entanto, direitos de propriedade robustos sobre o mundo (em contraposição à propriedade de si mesmo). Ver Rawls (1999, p. 54).

${ }^{12}$ A definição acima tenta ser, tanto quanto possível, agnóstica em relação às diferentes maneiras como a demanda igualitária é mais precisamente definida por liberais igualitários, os quais costumam divergir tanto quanto à base das comparações entre os cidadãos ou "métrica da vantagem" (isto é, se os cidadãos devem ser comparados com base nos recursos de que dispõem, em suas capacidades, oportunidades para o bem-estar, etc.) e quanto à forma do princípio a aplicar (princípio de igualdade em sentido estrito, princípio de prioridade para os cidadãos em desvantagem ou princípio de suficiência).

13 Uma questão independente é a de saber o quanto alterações do regime da propriedade, mesmo que conformes à justiça distributiva, devem ser evitadas ou, ao menos, protraídas em nome das expectativas fomentadas por um sistema jurídico injusto. 
Chamberlain de Nozick (1974, p. 160-161), estipulemos que a situação de distribuição inicial, D1, caracteriza-se por direitos de propriedade limitados de maneira a impedir que o clube de basquete entregue a Chamberlain vinte e cinco centavos do preço que cada fã paga para assistir ao jogo. ${ }^{14}$ Considere, então, as seguintes premissas:

1. Segundo o regime de propriedade vigente, o clube não pode nem poderá dar a Chamberlain vinte e cinco centavos do preço de cada ingresso.

2. Chamberlain sabe que, segundo o regime de propriedade vigente, o clube não pode nem poderá lhe dar vinte e cinco centavos do preço de cada ingresso.

3. O clube promete a Chamberlain, não obstante, vinte e cinco centavos do preço de cada ingresso.

Suponhamos que a restrição a direitos de propriedade recém aludida atenda a um imperativo de justiça distributiva. Segue-se que, para haver um conflito entre a justiça distributiva e o valor da promessa nas circunstâncias descritas, seria preciso que o valor da promessa subsistisse não obstante o fato de o promitente (no exemplo, o clube) ter prometido algo que não tem (e nem poderá ter) direito a fazer e de o promissário (no exemplo, Chamberlain) saber disso. ${ }^{15}$

A situação se complica na hipótese em que o promissário não saiba, nem devesse saber, que a promessa excede os limites do que ao promitente é lícito fazer. Em tal hipótese, essa promessa seria de molde a inspirar justificadamente a confiança do promissário, o que dá plausibilidade à tese de que a observância aos limites da justiça distributiva se faria ao custo do valor da promessa. Casos de ignorância escusável devem ser pouco comuns, no entanto, em circunstâncias ideais, nas quais o imperativo de certeza jurídica (um dos corolários do estado-de-direito) seja atendido.

Ressalva feita à hipótese do último parágrafo, o valor da promessa subsiste como valor independente da justiça distributiva sob as mesmas condições aludidas anteriormente com respeito à propriedade: a) no espaço de indeterminação deixado pelas várias maneiras de conformar o regime da propriedade sem afronta à justiça distributiva; b) nas circunstâncias não ideais de desatendimento à demanda distributiva, em que o regime jurídico da propriedade inclua, portanto, direitos de propriedade injustos (caso no qual a relação entre a justiça distributiva e o valor da promessa pode ser de genuíno conflito).

\footnotetext{
$14 \mathrm{O}$ regime da propriedade pode ser desenhado de modo a não admitir que Chamberlain e o clube contratem com a cláusula descrita por Nozick (a cláusula que dá ao jogador direito a vinte e cinco centavos do preço de cada entrada) ou a fazer com que essa cláusula perca efeito a partir de um certo ponto, evitando, assim, que Chamberlain enriqueça em demasia.

15 Para um exemplo extremo, considere o caso em que A promete a B que matará C, algo que (como B sabe) A não tem direito a fazer. Haveria algo a lamentar no fato de essa promessa não ser cumprida?
} 


\section{3. não coerção}

A exemplo do caso anterior, é difícil conceber - em circunstâncias ideais, ao menos - o valor da não coerção como valor em conflito com a justiça distributiva. Considerese mais uma vez uma situação de distribuição ideal D1 na qual a demanda igualitária esteja atendida. Nessa situação, uma das liberdades de A é a liberdade para $x$ - recusarse a contratar com B por um preço menor do que $p$. Suponhamos, ainda, que a liberdade para $x$ seja um imperativo da justiça distributiva, isto é, que uma situação de distribuição na qual A não fosse livre para $x$ seria não ideal, distributivamente falando. Soa implausível dizer então que, ao exercer $x$ (e recusar-se, portanto, a contratar com B por um preço menor do que $p$ ), A coage B. ${ }^{16}$ Seguem-se a respeito do valor da não coerção, portanto, as mesmas conclusões tiradas acima acerca da propriedade e da promessa. ${ }^{17}$

\section{4. responsabilidade}

Uma hipótese não cogitada nos itens acima é a de um conflito radical entre a justiça distributiva e os valores da propriedade, da promessa e da não coerção. Esse conflito teria lugar caso a demanda igualitária, ao invés de meramente condicionar esses valores, impusesse um modo de organização social incompatível com eles, isto é, determinasse a abolição da propriedade, do direito contratual e de outras instituições por meio das quais os valores da promessa e da não coerção possam se realizar.

Se a hipótese de um conflito radical envolvendo a justiça distributiva e os valores bilaterais acima é pouco plausível, o mesmo não se pode afirmar quanto ao valor da responsabilidade (entendido, tal como estipulado acima, como o valor de que A responda pelo dano que, sob certas condições causou a B). Há, de fato, razões tanto estritamente distributivas quanto de eficiência (às quais, aliás, a demanda igualitária não tem de ser insensível) para que o direito da responsabilidade civil seja substituído por instituições (como a regulação e o seguro) estranhas ao valor da responsabilidade. ${ }^{18}$

Não é o caso de entrar aqui no mérito das propostas de abolição da responsabilidade civil, nem, tampouco, de dar conta da intrincada literatura sobre o valor da responsabilidade. ${ }^{19}$ Basta, para as pretensões do artigo, reconhecer que a plausibilidade do argumento igualitário em favor do fim da responsabilidade enseja

\footnotetext{
16 Pensemos na plausível hipótese de que faça parte da demanda igualitária a liberdade de organização sindical. A tese do conflito dependeria, então, de afirmarmos que o exercício da liberdade de organização sindical (e as condições de trabalho que dele decorrem) ocorre em sacrifício ao valor da não coerção (a coerção de que é vítima, no caso, o capitalista).

${ }^{17}$ A análise se mantém basicamente inalterada caso queiramos substituir ou acrescentar ao valor da não coerção o da não exploração.

18 Para críticas à responsabilidade civil e propostas no sentido mencionado acima, ver Sugarman (1985); Alexander (1987).

19 Para uma sofisticada tentativa de defender o valor da responsabilidade, ver Perry (2001). Para exemplos de ceticismo, ver Alexander (1987); Hurd (1996).
} 
tratar o conflito entre justiça distributiva e o valor da responsabilidade como genuíno e não limitado às circunstâncias não ideais de inobservância da demanda igualitária.

\section{5. cuidado}

A oposição entre justiça distributiva e o valor do cuidado pode ter a seguinte forma: A tem uma obrigação de cuidado para com B para cujo cumprimento é necessário que A faça $x$; a justiça distributiva, no entanto, requer que A se abstenha de $x$ ou que as instituições obriguem A a abster-se de $x$ (caso prefiramos tratar os comandos da justiça distributiva como comandos endereçados às instituições). ${ }^{20}$

Esse conflito subsiste ainda que a obrigação de cuidado de A para com B seja uma mera obrigação moral e não um dever de justiça (isto é, que não se trate de uma obrigação cuja violação torne legítimo, sob certas condições, o uso da força contra A). Se os requerimentos da justiça distributiva (ou de instituições conformes à justiça distributiva) constituem um obstáculo ao cumprimento de uma obrigação moral, o problema não desaparece pelo simples fato de essa obrigação não ser daquelas cuja violação autoriza o uso da força.

Uma razão para pensar que o conflito entre justiça distributiva e obrigações de cuidado é menos sério do que pode parecer vem da suposição de que parte das nossas obrigações de cuidado subsiste apenas em condições não ideais de inobservância à justiça distributiva. Certas obrigações de cuidado dos pais para com os filhos, por exemplo, como a obrigação (de pais ricos) de prover educação paga, são, muito plausivelmente, obrigações limitadas a circunstâncias não ideais de violação ao princípio da equitativa igualdade de oportunidades. Sobre isso, no entanto, é preciso considerar duas coisas. Primeiro, que uma obrigação de cuidado somente exista em condições não ideais não impede que haja um conflito entre essa obrigação e deveres de justiça também existentes sob essas condições (os quais podem incluir o dever de agir individualmente para mitigar o impacto de instituições injustas). Segundo, nada autoriza supor que todas as nossas obrigações de cuidado desapareceriam sob condições ideais, de modo que a plena realização das demandas da justiça manteria vivo o risco de um conflito entre a justiça distributiva e o valor do cuidado.

Há, por fim, uma outra ressalva (além das ressalvas de praxe acerca da indeterminação da justiça distributiva e da possibilidade de conflito entre justiça distributiva e valores bilaterais em circunstâncias não ideais), que diz respeito à concessão que instituições liberais igualitárias talvez tenham de fazer à parcialidade ou, nos termos de Nagel (1991), a ações governadas pelo ponto-de-vista pessoal. Admitindo-se que a legitimidade conferida ao ponto-de-vista pessoal impõe limites ao que as instituições de uma sociedade justa podem requerer dos seus cidadãos (Cohen 2008, p. 10), é bem possível que por aí também se atenue a oposição entre a justiça distributiva e o valor do cuidado, já que o valor em questão costuma se realizar por

\footnotetext{
20 O valor do cuidado também é realizado por meio de atos que não constituam o cumprimento de obrigações (de nenhuma espécie), de tal maneira que a tensão entre justiça distributiva e cuidado também é instanciada por uma ação (não obrigatória) de cuidado $x$ no caso em que a justiça distributiva proíba $x$ ou requeira instituições que o pró́bam. Nada se perde com o fato de as considerações a seguir acima ignorarem essa possibilidade e se restringirem ao caso mais dramático de conflito entre justiça distributiva e obrigação de cuidado.
} 
meio de ações (não necessariamente obrigatórias ${ }^{21}$ ) que são candidatas plausíveis a pertencer ao "espaço imune à justiça" do ponto-de-vista pessoal.

\section{CONCLUSÃO}

Nem mesmo o que Scheffler (2015) chama de distributivismo forte - exemplificado pela aplicação irrestrita do princípio da diferença - implicaria a completa subordinação do direito privado, e dos valores bilaterais que esse direito costuma expressar, à justiça distributiva. Quanto a certos valores bilaterais, como a propriedade, a promessa e a coerção, instituições conformes à demanda igualitária (condições ideais) se limitariam a definir os moldes nos quais esses valores seriam realizados. Uma genuína oposição entre os valores em questão e a justiça distributiva só seria concebível, portanto, na hipótese de instituições distributivamente injustas (condições não ideais).

Em contrapartida, em relação a outros valores, como a responsabilidade e o cuidado, um conflito radical se mostra mais plausível. Em tal hipótese, a justiça distributiva requereria um desenho institucional incompatível com a realização do valor em jogo - como, por exemplo, um desenho institucional no qual a responsabilidade civil seja abolida. À medida que hipóteses assim se confirmem, a tensão entre o distributivismo liberal igualitário e os valores bilaterais do direito privado parece, de fato, inegável.

\section{REFERÊNCIAS}

ALEXANDER, Larry A. Causation and corrective justice: does tort law make sense? Law and Philosophy, v. 6, n. 1, p. 1-23, 1987.

COHEN, Gerald Allan. Rescuing justice and equality. Harvard University Press, 2008.

KORDANA, Kevin A.; TABACHNICK, David H. Taxation, the private law, and distributive justice. Social Philosophy and Policy, v. 23, n. 2, p. 142-165, 2006.

HURD, Heidi M. The deontology of negligence. BUL Rev., v. 76, p. 249, 1996.

NAGEL, Thomas. Equality and partiality. Oxford University Press, 1991.

NOZICK, R. Anarchy, State, and Utopia. Oxford: Blackwell, 1974.

${ }^{21}$ Ver a nota anterior.

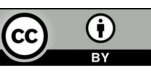


PERRY, Stephen R. Responsibility for outcomes, risk, and the law of torts. In:

POSTEMA, Gerald J. (org.). Philosophy and the law of torts. Cambridge University, 2001.

RAWLS, John. Political liberalism. Columbia University, 1996.

RAWLS, John. A theory of justice. Belknap, 2 ad., 1999.

RAWLS, John. Justice as fairness: a restatement. Belknap, 2001.

SCHEFFLER, Samuel. Distributive justice, the basic structure and the place of private law. Oxford Journal of Legal Studies, v. 35, n. 2, p. 213-235, 2015.

SUGARMAN, Stephen D. (1985). Doing away with tort law. California Law Review, v. 73, n. 3, p. 555-664. SUGARMAN, Stephen D. Doing away with tort law. Calif. L. Rev., v. 73, p. 555, 1985. 